\title{
PROPOSTA DE METODOLOGIA PARA ANÁLISE DOS GRUPOS ECONÔMICOS
}

\author{
Flávio Marcílio Rabelo \\ Professor Assistente do Instituto de Economia da Universidade \\ Estadual de Campinas e Coordenador Executivo do Projeto \\ "Grupos econômicos da indústria brasileira e a política econômica: \\ estrutura, estratégias e desafios".
}

RESUMO: Este artigo discute importantes questōes metodológicas relacionadas ao projeto "Grupos econômicos da indústria brasileira e a política econômica: estrutura, estratégias e desafios", pesquisa conjunta entre o Instituto de Economia da Universidade Estadual de Campinas e a Escola de Administraçāo de Empresas de Sāo Paulo da Fundaçāo Getúlio Vargas (EAESP/FGV). Analisa as estratégias corporativas dos grupos econômicos baseando-se nos conceitos de sinergia, competências básicas e produtos básicos. Aborda também a possibilidade de se construir tipologias úteis para o estudo do controle corporativo e das estratégias de diversificação, tendo como premissa que a gestāo dos recursos humanos é um elemento relevante para a compreensāo do comportamento estratégico dos grupos.

ABSTRACT: This article presents some important methodological questions related to the project "Economic groups of the Brazilian industry and economy policy: structure, strategies and challenges", a joint research involving the Instituto de Economia da Universidade Estadual de Campinas and Escola de Administraçāo de Empresas de São Paulo da Fundaçāo Getülio Vargas (EAESP/FGV). It analises the corporate strategies of these groups based upon the concepts of sinergy, core competences and core products and the possibility of creating a useful tipology to study corporate control and diversification strategies as well. The human resources management is considered a relevant element to understand the strategical behavior of economic groups.

PALAVRAS-CHAVE: grupos econômicos, estratégias corporativas, sinergias, negócios básicos, competências básicas.

KEYWORDS: business groups, corporate strategies, sinergy, core business, core competences. 
O Instituto de Economia da Universidade Estadual de Campinas e a EAESP/ FGV (Escola de Administração de Empresas de São Paulo da Fundação Getúlio Vargas) estão desenvolvendo o projeto "Grupos econômicos da indústrìa brasileira: estrutura, estratégias e desafios" ${ }^{\prime 1}$. Algumas características deste projeto merecem especial atenção. Em primeiro lugar, o seu objeto - grupos econômicos constitui um conceito ainda pouco definido na literatura brasileira sobre organização industrial, mas que parece crucial para uma compreensão mais precisa da atuação dos agentes econômicos privados. Em segundo, há o desafio metodológico ligado à execução do projeto: como captar os movimentos destes grupos, procurar uma lógica interna dos negócios envolvidos e compreender como esta lógica interna articula-se com a formulação de políticas macroeconômicas e industriais. Finalmente, o projeto envolve uma cooperação entre duas importantes instituições universitárias, evidenciando a necessidade de integrar análises econômicas e gerenciais.

O projeto "Grupos" trabalha com um universo de 43 grupos econômicos privados brasileiros e estrutura-se em torno de três eixos: o modo como estes grupos interpretam a política macroeconômica do governo e como esta política afeta suas decisões estratégicas; a lógica das estratégias de diversificação dos grupos econômícos, e a articulação dos aspectos organizacionais destes grupos (controle, propriedade, gestão, política de recursos humanos) com as estratégias corporativas. Neste artigo, exploram-se apenas questōes metodológicas referentes ao terceiro destes eixos.

\section{A. DINÂMICA DOS GRUPOS ECONÔMICOS}

Uma abordagem organizacional da dinâmica dos grupos econômicos deve centrar-se no conceito de estratégia corporativa. Uma estratégia corporativa lida com duas questões básicas: em que negócios a corporação (grupo) deve estar presente e como o escritório corporativo deve gerenciar a gama de unidades de negó$\operatorname{cios}^{2}$. É fundamental, pois, tentar compreender a lógica das diversificações do grupo. Três conceitos, a serem desenvolvidos

\section{Uma competência básica pode ser uma qualificação gerencial ou uma competência operacional. É preciso levar em conta que uma estratégia de longo prazo baseada na exploração de competências básicas reduz o escopo de possíveis diversificações do grupo.}

ao longo do artigo, fornecem a base para tal análise: sinergia, competências básicas (core competences) e negócios básicos (core businesses).

Dentro deste enfoque, deve-se estudar as formas de controle da administração corporativa (central) sobre as várias unidades de negócios que compõem o portfolio do grupo. O elemento importante desta análise é o grau de autonomia conferido aos gerentes responsáveis pelas unidades de negócios e a natureza da cobrança que lhes é feita. É importante verificar também a existência de mecanismos formais ou informais de coordenação entre a administração central e as unidades de negócios.

Além disso, o modo como os grupos econômicos reagem aos sinais da conjuntura macroeconômica e implementam ajustes, ou mesmo modificações mais profundas em suas estratégias, depende fundamentalmente de como estes sinais são interpretados pelos executivos do grupo. Isto significa que corporações submetidas a condições macroeconômicas semelhantes podem adotar comportamentos diversos, em função da maneira como seus executivos interpretam estas condições e imaginam suas perspectivas futuras. Este argumento aponta para a necessidade de analisar o processo decisório dentro dos grupos econômicos, remetendo assim à questão do controle e gestão. A literatura clássica ${ }^{3}$ deixou claro que há forte inter-relaçāo entre a formulação e implementação de estratégias e a estrutura organizacional. No processo de planejamento estratégico, os responsáveis não levam em conta apenas os
1. Gostaria de agradecer aos demais membros da coordenação do projeto pelas criticas e sugestóes, assim como pela permissão de publicar este artigo: Luciano $\mathrm{G}$. Coutinho (coordenador geral), Roberto Venosa e Margarida Afonso Baptista. O projeto é financiado pela Fundaçäo do Desenvolvimento Administrativo do Estado de São Paulo (FUNDAP), à qual também estendo meus agradecimentos.

2. PORTER, M. From competitive advantage to corporate strategy. Harvard Business Review. Boston, v. 65, n. 3 , p. 43-59, May/June 1987

3. CHANDLER Jr., A. D. Strategy and structure: chapters in the history of the American industrial enterprise. Cambridge (MA): The MIT Press, 1962: SCHEIN, E. H. Organizational culture and leadership. San Francisco: Jossey-Bass Publishers, 1985. 
condicionantes externos ao grupo, mas também as restrições $\mathrm{e}$ as potencialidades colocadas pela sua presente estrutura. A estrutura de um grupo, por sua vez, origina-se de processos mais profundos que têm sua origem nos valores dominantes do corpo gerencial ou na idéia de "cultura organizacional"4.

Numa outra perspectiva, a capacidade dos grupos econômicos de influenciar a política macroeconômica é condicionada pelo seu grau de articulação. Trata-se aí de analisar um fenômeno situado num nível intermediário entre as práticas gerenciais internas e os fatores nacionais e internacionais que definem as políticas macroeconômica e industrial. No caso japonês, paradigma para este tipo de estudo, verifica-se "uma rede corporativa marcada por uma elaborada estrutura de arranjos institucionais que organizaram suas companhias dentro de complexos padrões de concorrência e cooperação" ${ }^{\prime \prime}$. A tarefa, portanto, é desenvolver instrumentos de análise capazes de detectar a presença ou não de tais arranjos entre os grupos econômicos brasileiros.

\section{OS CONCEITOS DE SINERGIA, COMPETÊNCIA BÁSICA E NEGÓCIOS BÁSICOS}

\section{Sinergia}

Dois conceitos são úteis para se entender melhor a noção de sinergia: relatedness e lógica dominante de gestão. A relatedness entre dois ou mais negócios é fundamental para explicar seu potencial sinérgico. Pode ser pensada em dois níveis: o operacional, que compreende o uso de recursos comuns ou transferência de habilidades operacionais entre as cadeias de valor, e o gerencial, que corresponde à aplicação de qualificações gerenciais particulares aos novos negócios. A sinergia pode se dar, então, nos níveis operacional e gerencial.

\section{SCHEIN, E. H. Op. cit}

5. GERLACH, M. The Japanese corporate network: a blockmodel analysis. Administrative Science Quaterly, Ithaca, New York, v. 37, n. 1, p. 105-39, Mar. 1992.

6. VERY, P. Success in diversification: building on core competences. Long Range Planning. New York, v. 26, n. 5 , p. 80 92, Oct. 1993.

7. Idem, ibidem. lógicas gerenciais dominantes desenvolvidas através de experiências acumuladas nos negócios básicos da companhia"6.

A partir destas considerações, pode-se definir dois padrões de diversificação: situações em que a alta direção deseja gerenciar ela mesma os novos negócios neste caso, devem ser escolhidos negócios que possuam uma lógica gerencial dominante igual à desenvolvida na atividade básica - e situações em que a alta direção prefere ingressar em negócios que requerem lógicas diferentes - neste caso, deve-se reconhecer a necessidade de adquirir novas qualificações gerenciais. A alta direção precisa, então, avaliar se é factível aprender rapidamente uma nova lógica gerencial ou se é mais conveniente contratar um executivo qualificado para gerir o novo negócio.

Vale observar se houve decisão consciente da gerência de definir uma lógica geral de desenvolvimento para o grupo. Esta decisão pode ser a de formar um conglomerado ou então de constituir um conjunto de negócios fundado em alguma espécie de sinergia. É possível também uma combinação entre uma lógica financeira no nível corporativo e uma lógica sinérgica no nível de segmentos de negócios.

Competências básicas e negócios básicos

Para que se possa definir uma lógica geral de desenvolvimento, é preciso, inicialmente, definir as competências básicas do grupo, as quais irão determinar o caminho das futuras diversificações. Very ${ }^{7}$ aponta duas características importantes de uma competência básica: permite que a empresa domine, melhor do que os seus concorrentes, um fator-chave de sucesso de seus negócios e constitui uma barreira à entrada de novos concorrentes no negócio.

Em função destas características, uma competência básica deve propiciar vantagens competitivas e deve ser de difícil imitação pelos concorrentes. Uma competência básica pode ser uma qualificação gerencial ou uma competência operacional. É preciso levar em conta que uma estratégia de longo prazo baseada na exploração de competências básicas reduz o escopo de possíveis diversificações do grupo. Para explorar as sinergias, a alta direção do grupo precisa saber avaliar a 
relatedness gerencial e operacional entre os negócios.

Esta definição aproxima-se bastante da de Prahalad e $\mathrm{Hamel}^{8}$, que afirmam que uma competência básica: abre acesso a uma grande variedade de mercados (a Casio, por exemplo, desenvolveu uma competência em display systems, o que the permite participar do mercado de calculadoras financeiras, televisões miniaturizadas, monitores para PCs, laptops e visores de painel de automóveis); deve trazer uma contribuição significativa em termos de benefícios percebidos pelo cliente do produto final (caso do domínio da Honda na área de motores); deve ser algo difícil para os concorrentes imitarem, o que implica uma harmonização complexa de tecnologias individuais e habilidades produtivas.

\section{Nos negócios expostos à maior concorrência, em que a mudança tecnológica é intensa e há forte globalização, 0 importante parece ser explorar as sinergias.}

Do conceito de competência básica, pode-se derivar a noção de produto básico: "produtos básicos são os componentes ou submontagens que realmente contribuem para o valor do produ to final" I $^{\prime \prime}$. Săo exemplos desses produtos os compressores (na área de refrigeração) e os "motores" da impressora a laser.

A exploração de sinergias mediante competências básicas e produtos básicos fornece uma lógica para orientar a estratégia corporativa dos grupos. Essa lógica traduz-se no conceito de "arquitetura estratégica". A NEC, por exemplo, chegou a formar um comitê da alta direção para supervisionar o desenvolvimento de produtos e competências básicas. Em alguns casos, a estrutura descentralizada do grupo dificultou o foco nas competências. Isto quer dizer que para os grupos que exploram competências básicas uma arquitetura estratégica orienta os movimentos de diversificação de produtos e mercados.
Avaliação da relatedness gerencial

A suposição básica neste ponto é que o processo decisório de um gerente está ligado às situações organizacionais e ambientais por ele experimentadas. O conceito de relatedness gerencial está ligado, pois, às similaridades em termos de estrutura competitiva e fatores-chave para o sucesso entre o novo negócio e o negócio básico da companhia.

\section{Avaliação da relatedness operacional}

Uma estratégia de diversificação baseada na relatedness operacional pode ser dividida em extensão de capacidade e em aquisição de capacidade. No caso da extensão de capacidade, os critérios de seleção para aquisição de um novo negócio são o valor intrínseco do negócio e os recursos e qualificações que podem ser compartithados ou transferidos para a nova atividade, de tal forma que sejam dominados os fatores-chave da concorrência. A sinergia, neste caso, reforça a posição competitiva do grupo no novo negócio e, então, melhora os lucros esperados. Já na estratégia de aquisição de capacidade, o grupo entra num novo negócio (freqüentemente por intermédio de joint-ventures ou fusões) para adquirir uma qualificação específica. A idéia é que a transferência desta capacidade adquirida para o negócio básico do grupo reforce a posição do grupo nesta atividade.

\section{USO DE TIPOLOGIAS PARA ANALISAR ESTRATÉGIAS CORPORATIVAS}

Com base nos conceitos desenvolvidos, foram criadas algumas tipologias para estudar o estilo das diversificações das corporações. Convém mencionar que estudos recentes mostraram que muitas grandes companhias européias reestruturaram seus portfolios nas décadas de 70 e 80 , de modo a concentrar seus recursos em áreas relacionadas, do ponto de vista da concorrência ${ }^{10}$. A diversificação passa a ser justificada pela sinergia potencial entre os negócios.

\section{Tipologia de estratégias e estilos}

Uma tipologia recente e com boa aceitabilidade na literatura é a desenvolvida por Goold e Campbell e atualizada por Goold, Campbell e Luchs ${ }^{11}$. Os autores identificaram três estilos de valoriza-
8. PRAHALAD, C. K. HAMEL GARY. The core competence of the corporation. Harvard Business Review, Boston, v. $68, \mathrm{n}$ 3, p. 79-91, May/June 1990.

9. Idem, ibidem.

10. VERY, P. Op. cit., p. 81

11. GOOLD, M., CAMPBELL, A. Strategies \& styles. Londan. Basil Blackwell, 1987; G0OLD, M., CAMPBELL, A., LUCHS, K. Strategies and styles revisited: strategic planning and financial control. Long Range Planning. New York, v. 26, п. 5, p. 4960, 1993; _ . Strategies and styles revisited: "strategic control" - is it tenable? Long Range Planning, New York, v. 26, n. 6 , p. 54-61, 1993. 
ção adotados pela administração corporativa de grandes companhias diversificadas: controle financeiro, planejamento estratégico e controle estratégico. A hipótese é que o desempenho do grupo irá depender do ajuste ( $f$ it) entre o estilo gerencial adotado e o portfolio de negócios do grupo econômico.

\section{Grupos com controle financeiro}

Grupos com esse estilo gerencial caracterizam-se por praticar negócios isolados (stand-alone), orçamentos rígidos e metas financeiras de curto prazo. Tal estilo mostra-se mais apropriado quando o portfolio do grupo está focalizado em "negócios gerenciáveis", ou seja, aqueles que não necessitam de decisōes de investimento vultoso ou de longo prazo e que estão localizados em mercados relativamente estáveis. Os negócios que habitualmente compõem o portfolio destes grupos realizam investimentos relativamente pequenos e fazem incursões apenas experimentais em outras áreas.

Os autore ${ }^{12}$ mostram exemplos de companhias com controle financeiro que possuíam negócios em áreas como eletrônica, defesa e telecomunicações. O estilo gerencial não se mostrou apropriado a estes segmentos, uma vez que sua crescente globalização exige inter-relaçōes complexas e uma visão estratégica de longo prazo para preservar a competitividade. Uma das companhias que preferiu não se desfazer de seus negócios nessas áreas acabou por adotar um estilo mais estratégico, com maior gestão da coordenação entre os negócios outrora isolados. O controle financeiro, portanto, não é um estilo gerencial adequado quando a competitividade dos

12. GOOLD, M., CAMPBELL, A., LUCHS, K. Strategies and styles revisited: strategic planning and financial control. Op. cit., p. 50. negócios depende da exploração de sinergias. A administração central de companhias com este estilo não possui as capacitaçỏes para gerenciar negócios que requerem uma coordenação intensa e investimentos grandes e arriscados e que enfrentam acirradas batalhas competitivas nos mercados globais.

As companhias eficientes com estilo de controle financeiro são aquelas que conseguem identificar empresas subavaliadas no mercado, mal-gerenciadas e que podem beneficiar-se da capacidade de reestruturar negócios da administração central do grupo. Aliás, esta capacidade de reestruturar negócios constitui uma habilidade básica para as companhias que querem valorizar seus ativos com o estilo de controle financeiro. A chave do sucesso destes grupos está em saber adquirir, melhorar e vender os negócios que formam seu portfolio.

\section{Grupos com planejamento estratégico}

Em grupos com este estilo gerencial, os orçamentos e as metas tendem a ser mais flexíveis e são revistos dentro do contexto do desempenho tanto estratégico quanto financeiro. Estes grupos são administrados com uma visão de longo prazo. É um estilo apropriado para um grupo que tem em seu portfolio negócios com importante potencial sinérgico entre eles, e que necessitam, para manter sua competitividade, de decisōes arriscadas e de vulto. Este estilo apóia estratégias competitivas ousadas para seus negócios básicos, mas tem dificuldades quanto à gestão de negócios periféricos. Um problema freqüentemente encontrado nos grupos com este estilo é a tendência a burocratizar seu processo decisório. Ocorrem casos em que os gerentes das unidades de negócios se queixam da centralização das decisões na administração central e da dificuldade de implementar estratégias em virtude do excesso de burocracia. Trata-se ainda de um estilo que, para ser eficiente, requer que o grupo se concentre em alguns poucos negócios básicos. A diversificaçăo para fora destes negócios geralmente conduz a fracassos, em função da dificuldade de gerenciar eficientemente negócios que não são familiares aos altos executivos de grupos com planejamento estratégico.

Uma questão que deve ser discutida a respeito da experiência de grupos com este estilo é a dificuldade que as companhias 
encontram em explorar as qualificações desenvolvidas em seus negócios básicos em outras áreas.

Outra armadilha em que grupos com este estilo caem é a de tentar implementar estratégias que se mostram além dos recursos gerenciais e financeiros da companhia. Ocorre ainda a tendência de se tolerar por tempo demasiado um desempenho fraco em alguns dos negócios.

\section{Grupos com controle estratégico}

Em grupos com este estilo, verifica-se uma maior autonomia das unidades de negócios (em comparação com o estilo de planejamento estratégico), mas rígidos controles financeiros são enfatizados. Good et al. ${ }^{13}$ analisaram alguns grupos ingleses que, no final dos anos 70, adotaram este estilo em substituição ao de companhia centralizada ou holding. O que ocorreu nos grupos centralizados foi uma maior delegação de responsabilidade aos gerentes das unidades de negócios, bem como tentativas de melhorar o pensamento estratégico neste nível. Naqueles que se comportavam mais como uma holding, a mudança proporcionou maior controle da administração central sobre as antigas divisões independentes. Numa das companhias, o principal executivo decidiu criar em nível corporativo um comitê de desempenho e políticas, incluindo a si próprio, os principais diretores do grupo e os responsáveis pelas unidades de negócio, com o propósito de realizar revisões trimestrais. Em algumas destas companhias, a decisão de adotar o estilo de controle estratégico conduziu a esforços de redução de custos e à saída de negócios deficitários ou pouco lucrativos.

Os autores consideram que este estilo não é apropriado para grupos que se defrontam com o problema de gerenciar um portfolio diversificado de negócios, que não partilham características estratégicas comuns. Os grupos com controle estratégico procuram valorizar seus portfolios balanceando os controles estratégicos e financeiros. A experiência das empresas analisadas pelos autores mostrou como esta tarefa é difícil quando o portfolio é composto de negócios muito distintos e que se defrontam com questões estratégicas diferentes. Eles concluíram que não se sustenta a idéia tradicional de que uma estrutura descentralizada, unida a um sistema orça- mentário e de planejamento moderno, seria capaz de permitir a uma equipe gerencial corporativa competente adicionar valor a qualquer tipo de negócio.

Parece haver um consenso na literatura de que a diversificação em muitas áreas pouco relacionadas não é uma estratégia eficiente para os grupos econômicos. A única exceção seriam os grupos com um portfolio típico de controle financeiro. Nos negócios expostos à maior concorrência, em que a mudança tecnológica é intensa e há forte globalização, o importante parece ser explorar as sinergias.

\section{Tipologia de Porter}

Porter ${ }^{14}$ propôs quatro concepções de estratégia corporativa: gestão de portfolio, reestruturação, transferência de habilidades e partimento de atividades. As duas primeiras aproximam-se do estilo de controle financeiro proposto por Goold e Campbell ${ }^{15}$. De fato, um grupo analisado por Porter, como exemplo típico de um reestruturador bem-sucedido, é o Hanson Trust (Reino Unido), citado por Campbell e Goold como um modelo da eficiência do controle financeiro. As estratégias de transferência de habilidades e partimento de atividades, por sua vez, fundamentam-se na idéia de relatedness. É justamente esta idéia original de Porter que foi desenvolvida no trabalho de Very ${ }^{16}$ para melhor precisar o conceito de sinergia. Conclui-se, portanto, que a idéia de competências básicas, negócios básicos e sinergia estão por trás das principais propostas de classificação das estratégias corporativas.

Em relação à lógica mais estritamente financeira de diversificação (gestão de portfolio), vale a pena citar o argumento de Porter: "Na maioria dos países, os dias em que a gestão de portfolio era um conceito válido de estratégia competitiva pertencem ao passado. Em face de mercados de capitais crescentemente desenvolvidos, companhias atraentes, com boa gestão, aparecem nas telas de todos e atraem um alto valor em termos de prêmio de aquisi$\varsigma_{\tilde{a} o^{\prime \prime 17}}$. A pesquisa de campo realizada por Porter (relatos de diversificações de 33 grandes corporações norte-americanas, no período 1950-86) confirma afirmações dos outros trabalhos aqui citados quanto à dificuldade de gerir diversificações. Ele salienta o alto grau de insucesso verificado entre as corporações de sua amostra, sobretudo quando se tratava de aquisições
13. GOOLD, M., CAMPBELL, A., LUCHS, K. Strategies and styles revisited: "strategic control" - is it tenable? Op.cit.

14. PORTER, M. Op. cit.

15. GOOLD, M., CAMPBELL, A. Op. cit.

16. VERY, P. Op. cit.

17. PORTER, M. Op. cit., p. 51. 
18. Idem, ibidem, p. 5.

19. PRAHALAD, C. K., HAMEL, GARY. Op. cit., p. 87.

20. USEEM, M. Corporate restructuring and organizational behavior. In KOCHAN, T. A. USEEM, M. (eds.). Transforming organizations. New York e Oxford: Oxford University Press, 1992 não-relacionadas com a atividade principal do grupo. Seu achado importante neste particular é que a probabilidade de sucesso com diversificações aumenta à medida que a estratégia corporativa se aproxima da partilha de atividades e se afasta de gestão de portfolio.

A distinção feita por Porter quanto às diversificaçōes realizadas pelas corporações parece útil para o trabalho empírico: entrada em um setor ou campo inteiramen-

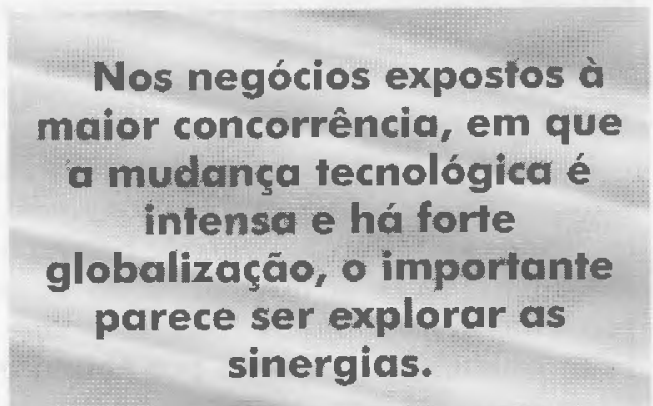

te novo; entrada numa nova indústria em um campo onde a companhia já atuava; e extensão geográfica de um produto ou serviço existente. Além disso, cada novo negócio foi classificado como relacionado ou não-relacionado a unidades existentes no grupo. Distinguem-se ainda as formas adotadas pelo grupo para cada diversificação: aquisição, joint-venture e criação de um negócio novo. Estes itens podem ser combinados para analisar os padrões de comportamento estratégico no que diz respeito às diversificações.

Recursos humanos e estratégias de diversificação

As práticas corporativas de gestão de recursos humanos podem servir de indicadores para estudar a estratégia corporativa. Porter observa, por exemplo, que a transferência de qualificações (característica de grupos que exploram competências básicas) requer uma política de recursos humanos coerente por parte da alta administração corporativa ${ }^{18}$. Para ele, a companhia terá de realocar pessoal críti$\mathrm{co}$, mesmo de uma forma permanente, entre as unidades de negócios, e o apoin da alta direção no processo de transferência de qualificaçōes é essencial.

No mesmo sentido, afirmam Prahalad e Hamel"1: "Achamos irônico que a alta direção gaste tanto tempo no processo de alocação de capital e, tipicamente, não possua nenhum mecanismo comparável para a alocação de qualificações humanas que incorporem competências básicas". É importante verificar se existem esforços por parte da alta direção do grupo para identificar pessoas dentro da organização que incorporem competências críticas e movê-las através das fronteiras da organização.

Certas práticas de recursos humanos, por exemplo, são indicativas de uma estratégia de explorar sinergias e articularse em torno de competências básicas. Entre estas práticas, podem-se mencionar as seguintes:

- exposição destes funcionários, logo no início de suas carreiras, a uma gama variada de negócios mediante um programa de rotação cuidadosamente planejado;

- designações periódicas a equipes de projeto multidivisionais para difundir competências básicas e afrouxar os elos que podem amarrar um indivíduo a uma unidade de negócio particular, mesmo quando surgem melhores oportunidades em outros lugares;

- acompanhamento da carreira destes individuos por profissionais de recursos humanos da própria corporação;

- reuniões regulares das pessoas que incorporam competências críticas nn grupo para criar um forte sentido de comunidade entre elas e para que sejam encorajadas a descobrir novas oportunidades de mercado.

A idéia é analisar os possíveis ajustes entre um certo conjunto de práticas na área de gestão de recursos humanos e a estratégia corporativa dos grupos econômicos.

\section{Controle e propriedade nos grupos econômicos}

Estudos recentes ${ }^{20}$ sobre a reestrutu-ração das corporações nos Estados Unidos destacam a mudança no controle acionário dos grupos como um dos principais componentes deste processo. Estes trabalhos apontam a tendência de ter maior envolvimento dos proprietários na gestão das corporações norte-americanas, questionando, assim, uma das premissas básicas da chamada "revolução gerencial": a separação entre propriedade e gestão. Não se trata, porém, de uma volta da influên- 
cia dos proprietários no sentido tradicional do termo; não são os fundadores nem as suas famílias que estão reassumindo controle, mas sim os investidores institucionais.

Estas mudanças no controle traduzemse em novos padrões de processos decisórios e de estruturação da corporação:

- a intensificação dos interesses dos proprietários pode levar a uma maior concentração do processo decisório no escritório central e à adoção de uma organização interna mais unitária. Verificouse, por exemplo, que grupos dominados pelos proprietários têm maior propensão a manter uma estrutura unitária em vez de multidivisional, quando comparados com grupos controlados por uma gerência desvinculada da propriedade;

- outros estudos ${ }^{21}$ apontaram que grupos cujas ações estão concentradas num pequeno número de acionistas tinham uma tendência significativamente menor à diversificação em linhas de produtos não-relacionados;

- ao mesmo tempo em que ocorre uma concentração do processo decisório das estratégias corporativas, as decisões operacionais tendem a ser descentralizadas nas empresas com forte influência dos proprietários. Isso se deve ao fato de que estas empresas trabalham com um staff reduzido e imprimem uma lógica de centros de lucro às suas unidades operativas.

\section{Particularidades importantes para a análise dos grupos brasileiros}

Deve-se levar em conta, sobretudo, que a grande maioria dos grupos econômicos nacionais são de controle familiar e, em alguns casos, gerenciados pela própria família. É uma situação totalmente diversa da encontrada nos países avançados, onde o controle dos grupos é bem mais pulverizado e a gerência, normalmente, é profissional. Isso já caracteriza uma situação peculiar. Dado este contexto, pode ser útil, ao analisar as estratégias de diversificação, distinguir: grupos econômicos nacionais controlados e gerenciados por famílias; grupos econômicos nacionais de controle familiar mas cuja gestão é entregue a profissionais; grupos econômicos nacionais de controle mais pulverizado e com gestão profissional; e grupos econômicos estran- geiros. No caso destes últimos, vale verificar como a estratégia de diversificação que adotam no país reflete a estratégia corporativa global do grupo.

Os grupos econômicos mais comumente tratados na literatura ocupam posições de liderança nos mercados e produtos em que atuam, freqüentemente competindo pela liderança mundial em certos segmentos. É pouco provável que algum grupo econômico nacional tenha uma proposta de tal envergadura. Isto certamente influi na estratégia corporativa e, portanto, na dinâmica das diversificações.

O mercado de capitais no Brasil é muito pouco desenvolvido. Grupos com uma lógica de natureza mais financeira para as suas diversificações dependem muito do comportamento e das sinalizações do mercado de capitais para procederem com planos de diversificação. Além disso, o controle pulverizado, mediado pelo mercado de capitais, coloca a alta direção do grupo sob a pressão constante do conselho de acionistas e do risco de um takeover hostil. No caso dos grupos brasileiros, é possível que a valorização do portfolio de negócios do grupo se confunda com a valorização do portfolio da família controladora, o que cria uma situação distinta daquela retratada na maior parte da literatura internacional.

\section{CONCLUSÃO}

Este artigo se propôs a apresentar algumas questões metodológicas relevantes encontradas no projeto "Grupos econômi$\cos$ da indústria brasileira e a política econômica: estrutura, estratégias e desafios econômicos", desenvolvido pela Unicamp e EAESP FGV. A possibilidade de tratarmos todas estas questões de forma adequada irá depender da qualidade das informações disponíveis. O conceito de estratégia é notoriamente fugidio; no máximo, consegue-se listar explicações ex-post para um fenômeno ocorrido. A proposta discutida é a de centrar a análise nos conceitos de sinergia e competências básicas. Baseados nestes conceitos, tentaremos verificar se é possível e útil construir tipologias de estilos de gestão e controle. Finalmente, acreditamos que a gestão dos recursos humanos e a questão da propriedade e gestão são itens importantes para completar a análise.
21. HILL, C. W. L., SNELL, S. A Effects of ownership structure and control on corporate productivity. Academy of Management Journal, v. 32 , p. 25-46, Mar. 1989. 